\title{
The Dangers of Separating Social Justice from Multicultural Education: Applications in Higher Education
}

\author{
Gloshanda Lawyer \\ University of Tennessee, Knoxville \\ U. S. A.
}

ABSTRACT: This article presents the case of the author's experience as a student in a multicultural education course. The exploration of this case expands on Cho's (2017) theoretical linking of social justice and multicultural education by highlighting the practical dangers of disengaging social justice from multicultural education. As an alternative to critiquing the field of multicultural education, this paper focuses on the execution of social justice in a multicultural education course. Both a social justice and a multicultural education lens are applied to analyze the author's experience in the course. Additionally, practical considerations are provided for those teaching multicultural education courses in higher education.

KEYWORDS: multicultural education, higher education, social justice, praxis, self-reflection

How I Came to Multicultural Education

Reflecting on Social Justice and Multicultural Education

Analyzing the Experience

Multicultural Education: Is it for Students Like Me?

Re-envisioning Praxis

Notes

References

Author Contact

Higher education is often the time when many future teachers are exposed to the socioeconomic, cultural, linguistic, ability, gender spectrum, and sexual orientation differences within the K-12 United States population. It is also the place where most future teachers are trained and educated alongside individuals from these various backgrounds, including those who bring transnational perspectives. This makes higher education the prime context for enacting social justice, with the potential of impacting K-12 education settings as well. For most teacher educator programs, multicultural education courses are typically the courses suggested to teacher candidates as the central place for learning about the diverse K-12 student population. Directing teacher candidates to multicultural education courses then allows program-specific courses to remain centered on content-area learning and pedagogical practices, rather than diverting class time to discussions of "diverse" populations. This practice necessitates grounding multicultural education courses 
strongly in social justice, not simply in what is taught but in how it is taught as well. As a formal student in a multicultural education course, and as an instructor and presenter on topics related to what would be considered "diverse" populations, I recognize that the teaching approaches used can either perpetuate or help to dismantle social injustices within multicultural education courses. Oftentimes, considerable preparation is placed on what content and topics to include in multicultural education courses. I argue that how the content and topics are approached, and how student engagement with the topics is facilitated, should be given as much consideration as what is taught. This article begins by providing a brief explanation of how I came to enroll in a multicultural education course. My journey is followed by a reflection on the social justice education and multicultural education literature synthesized by Cho (2017), which revisited literacies and frameworks of several contemporary scholars. I expand on Cho's (2017) work using Ukpokodu's (2016) four-part paradigm for transformative teacher education. Next, the discussion shifts to a reflection of my experience in a multicultural education course. I situate that experience in the context of Warren and Hytten's (2004) application of "faces of whiteness" and Applebaum's (2003) feminist perspectives. I then explore the question, "Is multicultural education really for students like me?" Lastly, this article explores practical ways in which social justice perspectives can impact instructor praxis in multicultural education courses.

\section{How I Came to Multicultural Education}

Upon reflecting on the state of the field of deaf education, specifically the hegemonic forces at play and the outcomes of the students educated under this system, I delved into the realm of cultural studies and social justice pedagogy. I began familiarizing myself with critical pedagogy (Freire, 1970; Giroux, 2009; McLaren, 2003), critical race theory in education (Ladson-Billings \& Tate IV, 1995), the spin-off movements of Critical Race Theory that I found particularly applicable to deaf education (e.g., Critical Deaf Theory [DeafCrit] (Gertz, 2003), Disability Critical Race Studies [DisCrit] (Annamma, Connor, \& Ferri, 2013), and Critical Language and Race Theory [LangCrit] (Crump, 2014)), and the asset pedagogies (e.g., Culturally Congruent Pedagogy (Au \& Kawakami, 1994), Culturally Relevant Pedagogy (Ladson-Billings, 1995), Culturally Responsive Pedagogy (LadsonBillings, 1994; Gay, 2000), and Culturally Sustaining Pedagogy (Paris, 2012)). McLaren (2003) stated that feminist pedagogy, cultural studies inquiries, social justice pedagogy, and multicultural education exemplify the re-invention of the critical pedagogy methodology. The search for the connection between critical pedagogy methodology and classroom praxis led me to the field of multicultural education. As a multilingual and multiethnic individual and one of the few people of color in the field of deaf education, I sought to understand why none of the aforementioned pedagogies and theories were applied to deaf education teacher preparation programs or in K-12 deaf education settings.

Comparing demographic information for deaf education and general 
education, the data are quite similar. In general education, $42 \%$ of multi-racial people are under the age of 18 (Jones \& Smith, 2001), one in five children enrolled in schools is an immigrant to the United States (Goodwin, 2002), 50 languages are used by at least 10,000 school-aged children (Rong \& Preissle, 1998), and $13 \%$ of school-aged children are considered dis/abled ${ }^{1}$ or receive disability services (Scull \& Winkler, 2011). In a survey of 10,500 students in grades $6-12,81 \%$ reported experiencing discriminatory practices in school due to their gender and/or sexual orientation identities (Kosciw, Greytak, Giga, Villenas, \& Danischewski, 2016). Similarly, in deaf education, $50 \%$ of deaf children are from racialized backgrounds (Simms, Rusher, Andrews, \& Coryell, 2008; Reagan, 1985), 40\% are diagnosed with medical and/or educational dis/abilities (Gallaudet Research Institute, 2013), and the population has the same socioeconomic status ratios as the United States as a whole (Pray \& King Jordan, 2010) with a growing number of deaf children being born to a low SES background (Reagan, 1985).

The student demographic is in stark contrast to the professionals who work in both the deaf education and general education fields. Though much has changed in the U.S. population demographics since the birth of multicultural education and the formal beginning of deaf education 200 years ago, those who control the schools and classroom micro-cultures are predominantly White, U.S.born, and Christian; have a monolingual upbringing; are generally from a middleclass socioeconomic status; identify as women, heterosexual, and abled, ${ }^{2}$ and are from individualist cultures (Goodwin, 2002; Sleeter, 2008). Further complicating the issue in the deaf education context, $90 \%$ of teachers of the deaf are hearing and $90 \%$ are White (Simms et al., 2008). Also, the teachers who enter the field typically have little to no exposure to the Deaf and Disabled cultures until they enter their teacher preparation programs, which lamentably is also generally when they begin learning American Sign Language.

As one who belongs to the majority group of hearing teachers in the field, I recognize the learning-unlearning process in which I have had to engage, and continue to engage, in order to honor the cultures of Deaf, DeafBlind, DeafDisabled, and Hard of Hearing (DDBDDHH) individuals. ${ }^{3}$ As one who belongs to the minority group of teachers of color in the discipline, my own experiences of marginalization due to my identities have also contributed to my ability both to understand the fight for justice within the field of deaf education and to work in solidarity with professionals from the DDBDDHH cultures to transform the field. So it was with this context in mind that I sought to better understand multicultural education. Specifically, I wanted to understand why multicultural education courses were a distinct discipline separate from general teacher preparation courses. This pondering led me to enroll in a multicultural education course within the cultural studies department at a predominantly White institution in the southern part of the United States. 


\section{Reflecting on Social Justice and Multicultural Education}

In an article published in a previous issue of this journal, Cho (2017) made the theoretical case for why teaching for social justice and multicultural education must be aligned to promote social justice effectively. Cho argued that social justice should be inherent in multicultural (teacher) education. Cho further supported the case for the marrying of social justice and multicultural education by uniting the work of five female scholars who have written in the areas of social justice and/or multicultural education. Cho also called for scholars to better link teaching for social justice and multicultural education within the literature. In this way, social justice would extend beyond social activism and beyond exploring hegemony within society. Social justice would, in fact, take on issues of educational policy and practice.

Cho (2017) made a powerful case for social justice and multicultural education by connecting North's (2009a) social justice literacies to Gay's (2012) goals of multicultural education. North (2009a) detailed five social justice literacies to envision a democratic education: functional (access to power structures); critical (emancipation of the oppressed); relational (caring in culturally appropriate ways and the breakdown of traditional teacher-student roles); democratic (participation in local, national, and global levels to advance an agenda of justice); and visionary (the acknowledgement of obstacles but hope for a future in which students are contributors). Unifying the works of Christine Bennett, Christine Sleeter, Carl Grant, and James Banks, Gay's (2012) goals for multicultural education were divided into four areas: academic, social, political, and cultural. Cho (2017) claimed that "deliberate integration of social justice literacies...contributes to meeting the comprehensive goals of multicultural education and to promoting social justice" ( $p$. 12).

Ukpokodu (2016) also argued a four-part paradigm for transformative teacher education practice: institutional cultural transformation, pedagogical transformation, curriculum transformation, and faculty transformation. Within the pedagogical transformation, Ukpokodu (2016) envisioned a four-part paradigm that included social justice perspectives, multicultural perspectives, global perspectives, and excellence perspectives. Ukpokodu (2016) asserted that all parts of the paradigm were interrelated and thus necessary to accomplish the goal of pedagogical transformation. It is evident that the scholars in the fields of social justice and multicultural education agree with Cho's (2017) assessment of the need to address social justice and multicultural education as interrelated entities. Beyond the literature, however, is this interrelatedness translating to multicultural education courses? 


\section{Analyzing the Experience}

My own experience as a student in a multicultural education course presents an opportunity to interrogate the connection of the literature on social justice and multicultural education to classroom praxis at the higher education level. Though this experience is based on a single case, it can be used to highlight the dangers of teaching multicultural education courses using approaches that are not grounded in social justice.

\section{The Context}

My experience was situated in a semester-long multicultural education course at a predominantly White institution. The course was one of many course options that fulfilled a requirement for a cultural studies certificate. All but one of the roughly 25 students in the course were at the graduate level. I was one of three people of color, all of whom were born in the United States. One of the students of color identified as physically disabled. Additionally, there was one international student who came to the United States in adulthood. The remaining students in the course identified as White and heterosexual. The professor of the course identified as a White, heterosexual woman.

The expressed goals of the course included: (a) exploring the sociocultural backgrounds of the students enrolled in the course; (b) understanding multicultural education as social justice; and (c) using critical multiculturalism to challenge discriminatory educational praxis that is rooted in racism, sexism, heteronormativity, and classism. The course was organized to cover a different topic in sociocultural backgrounds each week. Weekly readings related to the week's specific identity marker (e.g., sexual orientation, race, religion, etc.). The issues were explored through whole-class and small-group discussions. The whole-class discussions consisted of the students and the teacher going around the room sharing how they personally identified with each week's identity marker (e.g., the religious upbringing you had and how you currently identify today). Smallgroup discussions consisted of reactions to the week's readings. Additional course requirements included online discussion posts by students-required to be written from the perspective of a chosen "other"-and a final autobiographical paper that should include all the identity markers discussed throughout the semester.

\section{Faces of White (Able, Cisgender, Monolingual)-ness}

In a critical ethnographic study of teachers enrolled in a graduate-level 
course on whiteness, Warren and Hytten (2004) found that students fell into four problematic categories that they labeled "faces of whiteness" (p. 323): "The Torpefield," "The Missionary," "The Cynic," and "The Intellectualizer." "The Torpefield" is representative of students who are completely shocked at learning that they oppress and feel so self-consumed that they are unable to act. Guilt, embarrassment, and regret are typical characteristics. "The Missionary" is tired of the rhetoric and ready for action. Typical characteristics include desire for immediate action and a helper complex. "The Cynic" is the pessimist and believes the issue at hand is too large to change. They, in their extreme form, choose inaction and cease discussions by dismissing them as a waste of time. Lastly, "The Intellectualizer" wants to learn and seeks information. However, what they learn does not generalize or translate to their daily life or self-reflection.

In their article, Warren and Hytten (2004) discussed the more extreme versions of each "face." Each of these faces was present in my course in subtler forms. For example, "The Torpefield" was represented by the student who came from a financially well-to-do family from a major urban city suburb. This student had never heard of the issues discussed in the course prior to arriving to the university. "The Missionary" was represented by the White, female K-12 teacher who now worked with students who predominantly used Spanish and whose parents barely spoke English. "The Cynic" was the older male who identified as being in an interracial marriage and having biracial children. "The Cynic" also felt that some people just were not going to change, so it would be best to avoid them. "The Intellectualizer" of the class was a White male who came from an educated, professional family and had returned to academia after a professional sports career. "The Intellectualizer" wanted to have conversations and learn more about other people's experiences. "The Intellectualizer" could even acknowledge his own privileges. Unfortunately, this knowledge did not always incite him to action within the context of this course.

To understand the necessity for social justice, it is important to understand how these "faces" shaped the classroom dynamics and dialogues. It is also important to understand that, as Warren and Hytten (2004) explained, the "faces" changed based on the identity marker that was centralized for the week. Triggering statements were made in every class session, without fail. Some sessions would feature "The Missionary" discussing how someone needs to do something to "help" the sad children whose families do not understand the U.S. education systems. Other sessions would involve "The Cynic" arguing with me about whether inequities and prejudices exist in the world. However, societal inequities and prejudices are rarely based on race; they are more based on "differences," such as a person having a "preference" for not liking the sound of Spanish. "The Cynic" would say there was only one race- the human race-and that any action of bias against an individual could rarely be proven, without a shadow of doubt, to be attributed to race. During one small-group discussion after minutes of unavailingly "debating" with "The Cynic" on white privilege, I finally firmly and angrily said, "As a White male, you cannot tell me to prove when a situation is race-related or not," to which my peer responded: "As a White male, you can't tell me I can't have an opinion about it." 
Yet these "faces" were not limited to race. Comments circulated asserting that people with physical disabilities could not be doctors and nurses. When the student who has a physical disability retorted that there are laws against discriminating based on ability, the majority members centered their responses on the 50-pound lift requirement imposed on doctors and nurses. To this, the Disabled individual countered with the fact that there are plenty of doctors who are "dis/abled" regardless of whether the disability is apparent or not. Related to gender, one "Intellectualizer," who identified as a feminist, requested to know everyone's pronouns yet repeatedly misgendered an individual (not enrolled in the course), despite being subtly and directly reminded. Concerning language, another "Intellectualizer" discussed the importance of individuals maintaining their languages yet admitted their spouse and children did not use their native language, and the "Intellectualizer" saw no reason to encourage them to use their native language. Nevertheless, there is no question that these individuals all enrolled in this course with the intention of learning and/or applying what they learned. It is my belief that those who design and implement multicultural education courses have the responsibility to address each "face" and others not discussed here. Those who design and implement multicultural education courses also have the responsibility to journey with students into transformation. For that reason, I want to focus my critique on the actions of the course instructor in response to these types of classroom situations.

\section{Social Justice Critiques}

Applebaum (2003) framed moral agency as the "capacity to choose and act in accordance with judgments about what is right and wrong" (p. 253). Applebaum delved into explaining how the situatedness of moral agency can cause members of the dominant group to unintentionally perpetuate and support oppressive social systems. Applebaum made the case that if dominant group members are committed to social justice, they should be concerned with moral agency. Given that one of the overarching course goals was to understand multicultural education as social justice and given that the instructor of this course self-identified with many dominant groups (i.e., White, abled, heterosexual, having access to functional literacies), the lack of evidence of moral agency is particularly applicable to the critique of this multicultural education course. In the case of the class consensus on dis/ability, the professor's failure to address structural inequities and barriers to access and accessibility forced the only Disabled student in the class to defend both the rights and the agency of all dis/abled individuals. The students' reference to the 50-pound lift requirements presented the professor with an opportunity to support the students in affirmatively owning up to the ignorance of their statements (North, 2009b); however, the professor's missed opportunity left the Disabled student to provide that teaching.

The situation of "The Cynic" and the racism debate with me is best described by Applebaum (2003): "Unintended patterns of discourse subtly absorbed from 
associations with dominant group privilege create expectations in dominant group members that their concerns must always be addressed and that they will be in control" (p. 258). Thus, being allowed to have an opinion and explain why a marginalized person's daily experience is not evidence enough of a phenomenon, a phenomenon that "The Cynic" will never experience, is a privilege only afforded to dominant group members. The teacher's decision not to intervene reified the dominant position of "The Cynic" and my subordinate position. This discourse pattern is typical of dominant group members, the group to which the instructor also belonged. Therefore, no intervention may have seemed warranted from the instructor's perspective. In an outline of critiques of multicultural education from the Left and the Right, Nieto $(1995,2009)$ touched on the superficial acceptance of diverse perspectives, which can lead to the dangerous assumption that all perspectives are equal and valid. It is possible to analyze the professor's choice not to challenge "The Cynic" through this lens. In other words, the professor potentially chose not to intervene because she believed that "The Cynic's" opinions on racism were equally valid as mine from a Person of Color. It is impossible to know what was in the professor's mind in that moment. However, what I can communicate with certainty is how triggered and disillusioned this situation left me, especially since there was no debriefing or check-in by the professor afterwards.

\section{Multicultural Education: Is It for Students Like Me?}

These experiences left me pondering the question: Are multicultural education courses at the university level really for people like me? A great deal of the literature in multicultural education centers on $\mathrm{K}-12$ schooling. A pedagogy grounded in social justice is one that allows students to construct and use knowledge to become agents of change on individual and societal levels (Oakes, Lipton, Anderson, \& Stillman, 2016). At the higher education level, Ladson-Billings and Tate IV (1994) found that multicultural education was more concerned with curriculum and including diverse histories and experiences. Since then, the multicultural education literature based in the United States has expanded. Increasingly, the discourse is shifting to centering multicultural (teacher) education at the university level with emphases on preparing (White) students and approaching defensiveness and resistance (see Sleeter, 2008; Ukpokodu 2002, 2010).

Another factor to acknowledge is that multicultural education courses can be the first introduction to diverse perspectives and social issues for most students. Moreover, if the multicultural education course is centered on teacher preparation, these same students are also tasked with learning how to teach with diverse perspectives and social justice in mind. Ukpokodu's (2010) study affirmed this. Ninety-five percent of the participants in the study had never taken a diversity course prior to the study. All students were at the graduate level and $67 \%$ of the participants were White. With the demographics of the teaching profession and the paucity of experience these teachers have with diverse populations, it is a safe 
assumption that multicultural education courses must be prepared with White, female, monolingual, heterosexual teachers in mind. Ukpokodu's (2016) literature synthesis found that after 50 years of multicultural education, new and veteran teachers in $\mathrm{K}-12$ settings continued to struggle with teaching students from linguistic, cultural, racial, and class backgrounds that were different from their own. This leads to the question whether those who teach multicultural education courses at the higher education level also struggle to teach diverse student populations. As demonstrated in the above sections, multicultural education courses can become a triggering space for students enrolled in the course who already come from marginalized backgrounds. The potential for multicultural education courses to be unsafe spaces increases when the course and the management of classroom interactions are not grounded in social justice. Are instructors of multicultural education courses prepared and preparing for the experiences of students like me, with intersectional identities, to be enrolled in the course? The experiences I described are only a few examples from the semesterlong course. It is my belief that my experience with the course content, design, and activities as a person who is marginalized and minoritized in society is not unique. If the examples I have described are not my singular experiences, careful deliberation of ways to make the multicultural education course considerations inclusive of students like me are warranted.

Very little literature explores the experiences of marginalized and minoritized students in multicultural education courses. Failing to design and implement multicultural education courses with students like me in mind poses two dangers. First, the experiences I described in a multicultural education course become the norm, and the field loses marginalized and minoritized students who may have become teachers. Second, without grounding the course in social justice, there is a great potential for marginalized students to perpetuate the marginalization of other marginalized groups. For example, a student who experiences societal marginalization based on race might marginalize a Disabled student based on ability. Likewise, a White Disabled student could marginalize an abled student of color based on race, etc. This is a legitimate concern when many multicultural education course instructors take the approach of essentializing identities to teach about multicultural perspectives. Therefore, teaching with social justice in mind could inform how multicultural perspectives are presented throughout the course.

Yet multicultural perspectives compose only one part of Ukpokodu's (2016) proposed pedagogical transformation. Social justice perspectives, global perspectives, and excellence perspectives complete the four-part paradigm for pedagogical transformation. Though my course instructor was intentional about incorporating global perspectives, multicultural perspectives, and excellence perspectives, social justice perspectives were lacking. Ukpokodu (2016) defined social justice perspectives as pedagogy that "involves the intentional, explicit, and systematic integration of social justice issues" (p. 130). My experiences of the negative impact of neglecting social justice perspectives support Cho's (2017) call for more theoretical, and I would add pedagogical, linkings of social justice and 
multicultural education.

Cho (2017) developed an integrated framework for multicultural education and social justice by theoretically linking several women scholars from both social justice teaching and multicultural education. Cho stressed the importance of integrating North's (2009a) social justice literacies, Gay's (2012) purposes for multicultural education, Sleeter's (2015) dimensions of social justice teaching, and Dover's (2009) framework for teaching for social justice in order to evaluate current practice in K-12 education settings and promote social justice. Although Cho's (2017) discussion did not extend to higher education multicultural education courses, the integrated framework could also serve as guidance for instructors of multicultural education courses. Some guiding questions that multicultural education course instructors could derive from Cho's (2017) integrated framework include: What social justice literacies will I address in this course? How will I integrate marginalized perspectives and explicitly address issues of inequity and power within the course? Does my teaching pedagogy include the implementation of interventions that develop intercultural competence, address dysconscious prejudices, and address dominant group resistance? Framing a multicultural education course around these three questions is a start to designing and implementing a course that is as much for me as it is for my dominant-group member peers.

\section{Re-envisioning Praxis}

If multicultural education courses are indeed as much for people like me as they are for those who form the majority in the teacher and teacher education fields, I suggest a few praxis-level considerations for instructors at the higher education level. Gay (1995) stated that the "capstone of the empowerment process is translating new knowledge, values, and skills into action strategies designed to reform society" (p. 179). Although my course instructor imparted knowledge to students, there was never a discussion of how to address inequities and injustices. There were some students who were knowledgeable about some structural injustices and oppressions, yet they did not know what to do with this knowledge. The gap between those of us who live what others are learning causes a tension. For many of the students being enlightened to these realities, having a classmate become the human face to connect with class topics impacts both the student who is learning as well as the student who is now forcibly noticeable. Acknowledging this tension should be the responsibility of the instructor. Beyond acknowledging this tension, the instructor should help students who are newly learning about social and educational inequities to know what to do next. Instructors should be able to direct those students to the appropriate places for asking more questions so that the burden is not on the student who represents the "other." The professor should also provide directions for how to learn from marginalized and minoritized groups without intruding on their safe spaces.

Community resources and social media can be great tools for learning in non- 
intrusive ways. Using these tools is also a way to re-envision praxis, as the voices provided in the course would extend beyond books and articles written by dominant group individuals. Instructors of multicultural education courses should undertake challenging the institutional inequities that prohibit marginalized voices from having access to functional literacy. Barriers to functional literacy have resulted in fewer academic publications by individuals from marginalized backgrounds. Therefore, selecting sources by marginalized individuals, though they may not be academic, provides perspectives that dominant group individuals have not historically encountered. Cho's (2017) argument for extending social justice beyond social activism is a crucial one. Cho engaged in scholarly activism by intentionally selecting five female social justice and/or multicultural education scholars to counter the male-dominated discourse. This form of intentionality is one that instructors of multicultural education courses could and should implement. Additionally, the act of including and replacing, when possible, dominant voices with those of individuals from diverse marginalized communities should be made explicit to students enrolled in multicultural education courses. Making this action explicit could help aid student understanding of why these perspectives are needed and why they are typically absent from the mainstream discourse.

Gay (1995) also asserted that "opportunities must exist for students to engage in anti-oppressive struggles, to link ethical values with political actions, and to apply skills of justice, autonomy, and reciprocity" (p. 179). This includes managing overt and dysconscious oppressions within the classroom. North (2009b) found that certain situations necessitated interrupting. However, I argue that taking the opportunity to work through these situations with students is a necessary step to move beyond interrupting the (dysconscious) oppressive behaviors or biased beliefs students may have. As a student who was triggered by oppressive statements and having the privilege card invoked against me in a heated debate, I would have felt much more healing had I been able to watch the professor address this situation and convert it to a learning experience for my classmate rather than witnessing the situation being completely erased.

Multicultural education course instructors should also consider the space they want to create for the class. Small-group arrangements that place one Person of Color (or any marginalized group) per group of dominant individuals create an unsafe situation for the marginalized student. Although this seems like an opportunity for the dominant group members to learn, our existence and inclusion should not be determined by the gaze and the needs of the dominant group. In the words of Patricia Williams (as cited in Applebaum, 2003), "the choice of identifying as [name marginalized group] [becomes] hardly mine" (p. 258). This is what it means to be forcibly noticed.

Lastly, Nieto (1995) discussed a Leftist critique of multicultural perspectives as decontextualized. This critique is applicable to the context of the design of the multicultural education course described in this article. The decontextualization of multicultural perspectives was a hallmark of the course since the course was specifically designed to explore each identity marker separately. North (2009b) held that teaching strategies that address how oppressions intersect and sustain 
one another hold more potential for interrupting those oppressions. At times, it is necessary to explore one issue in isolation to facilitate understanding. However, all oppressions and -isms are interrelated and cannot be addressed in isolation. Therefore, if a week focuses on one aspect of identity, discussions should also include examples of how that identity can and does intersect with other identity markers. Without naming and exploring the connection between oppressions, there is not much potential for interrupting them.

I have provided only a few ways that praxis in multicultural education courses can be re-envisioned. My recommendations for instructors are to address the following:

1. Acknowledge the tension between students who live the course content and those who are learning from an outsider's perspective;

2. Provide direction to students for where to ask more questions;

3. Challenge institutional inequities by using resources (academic and nonacademic) from marginalized/minoritized perspectives;

4. Make social justice activism within the course explicit to the students;

5. Interrupt oppressive behaviors and convert them into moments to engage;

6. Create spaces that protect the autonomy of the marginalized students, allowing them to choose to educate their peers or remain in the background,

7. Explore the intersections of oppression along with identity markers in order to disrupt them when they manifest in the course and within educational systems.

I believe these praxis recommendations could offer a few ways to extend Cho's (2017) integrated framework into higher education. Furthermore, these recommendations could extend this framework from theory into practice. My perspectives are those of a student outside the field of multicultural education. It is always advisable to consider and tailor actions within the classroom with the end of social justice, based on the exposure and experience of the students enrolled in the course. After all, the ultimate goal is for changes in educational systems as well as society at large.

\section{Notes}

1. Within the field of Disability Studies and in social justice spaces, this term is used to recognize the lived experience of both individuals whose bodies and/or minds function differently and individuals who have medical and/or educational diagnoses as well as to acknowledge disability as a social construct which changes based on how it benefits those in power to "other" certain bodies/minds and groups of people. 
2. My use of the term "abled" is a result of a Twitter thread posted on March 21 and 22, 2017 by a Disabled Autistic individual, Eb [@EbThen]. Within the thread, Eb explained that "abled-bodied" is typically used to simply refer to anyone who does not have a disability. However, this use is incorrect for many reasons, including that it generally focuses on apparent disabilities and negates the subject of the mind. In contrast, the term abled refers to both the body and mind (regardless of whether the disability is apparent or not).

3. Although the literature uses "deaf" to refer to individuals who consider themselves to have a medical deficit, "Deaf" to refer to individuals who are part of the cultural group that uses American Sign Language (in the United States), and "Deaf Plus" or "Deaf with Disabilities (DWD)" to refer to individuals who have disabilities in addition to being d/Deaf, the communities of individuals with the lived experience of being DDBDDHH created this acronym to collectively address what the literature considers to be deaf, Deaf, and Deaf Plus/DWD. This is the members' way of resisting being named by those in power as well as an act of solidarity with the Disabled community. See Burke's (2013) blog post on this topic: Burke, M. (2013, March 13). SPEAKOUT: Deaf or Disabled, Deaf and Disabled, or DeafDisabled? [Web log post]. Retrieved from http://www.thebuffandblue.net/?p=11156

4. Warren and Hytten (2004) described "faces" as fluid and as a "temporal space that one enters into and speaks from" (p. 323).

\section{References}

Annamma, S. A., Connor, D., \& Ferri, B. (2013). Dis/ability critical race studies (DisCrit): Theorizing at the intersections of race and dis/ability. Race Ethnicity and Education, 16, 1-31.

Applebaum, B. (2003). Situated moral agency: Why it matters? In B. J. ThayerBacon, L. Stone \& K. M. Sprecher (Eds.), Education feminism: Classic and contemporary readings (pp. 253-262). Albany, NY: State University of New York Press.

Au, K., \& Kawakami, A. (1994). Cultural congruence in instruction. In E. Hollins, J. King, \& W. Hayman (Eds.), Teaching diverse populations: Formulating knowledge base (pp. 5-23). Albany, NY: State University of New York Press.

Burke, M. (2013, March 13). SPEAKOUT: Deaf or Disabled, Deaf and Disabled, or DeafDisabled? [Web log post]. Retrieved from http://www.thebuffand blue.net/?p=11156

Cho, H. (2017). Navigating the meanings of social justice, teaching for social justice, and multicultural education. International Journal of Multicultural Education, 19(2), 1-19.

Crump, A. (2014). Introducing LangCrit: Critical language and race theory. Critical 
Inquiry in Language Studies, 11(3), 207-224. doi: 10.1080/15427587. 2014.936243

Dover, A. (2009). Teaching for social justice and K-12 student outcomes: A conceptual framework and research review. Equity and Excellence in Education, 42(4), 506-524.

Eb [EbThen]. (2017, March 21). FYl: able-bodied is not the opposite of Disabled and please stop using it like it is. [Tweet] Retrieved from https://twitter.com/EbThen/status/844365738546778112

Eb [EbThen]. (2017, March 22). Abled is fine. Non-Disabled, if you don't like "abled." But not able-bodied when you mean those first things. [Tweet]. Retrieved from https://twitter.com/EbThen/status/844368196010479618

Eb [EbThen]. (2017, March 22). It's inclusive and doesn't focus on what we consider "physical" impairment. [Tweet]. Retrieved from https://twitter.com/ EbThen/status/844454783901732866

Eb [EbThen]. (2017, March 22). Because of the way Western thought views body and mind as separate, "able-bodied" is generally read as including neurodivergent folks. Retrieved from https://twitter.com/EbThen/status/ 844453938120265730

Freire, P. (1970). Pedagogy of the oppressed. New York, NY: Herder \& Herder.

Gallaudet Research Institute (GRI). (2013). Regional and national summary report of data from the 2011-2012 Annual Survey of Deaf and Hard of Hearing Children and Youth. Washington, DC: Gallaudet University.

Gay, G. (2012). Multicultural education, purposes, and goals. In J. A. Banks (Ed.), Encyclopedia of diversity in education (pp. 1548-1553). Thousand Oaks, CA: Sage.

Gay, G. (2000). Culturally responsive teaching theory, research, and practice. New York, NY: Teachers College Press.

Gay, G. (1995). Mirror images on common issues: Parallels between multicultural education and critical pedagogy. In C. E. Sleeter \& P. L. McLaren (Eds.), Multicultural education, critical pedagogy, and the politics of difference (pp. 155-189). Albany, NY: State University of New York Press.

Gertz, E. N. (2003). Dysconscious audism and critical Deaf studies: Deaf crit's analysis of unconscious internalization of hegemony within the Deaf community. (Unpublished doctoral dissertation). University of California Los Angeles, CA.

Giroux, H. A. (2009). The attack on higher education and the necessity of critical pedagogy. In S. L. Macrine (Ed.), Critical pedagogy in uncertain times (pp. 11- 26). New York, NY: Palgrave MacMillan.

Goodwin, A. L. (2002). Teacher preparation and the education of immigrant children. Education and Urban Society, 34(2), 156-172. 
Jones, N., \& Smith, A. (2001). The two or more races population: 2000 (Report). Washington, DC: US Census Bureau.

Kosciw, J. G., Greytak, E. A., Giga, N. M., Villenas, C., \& Danischewski, D. J. (2016). 2015 National School Climate Survey: The experiences of lesbian, gay, bisexual, transgender and queer youth in our nation's schools. New York, NY: Gay, Lesbian, and Straight Education Network.

Ladson-Billings, G. (1995). Toward a theory of culturally relevant pedagogy. American Educational Research Journal, 32(3), 465-491.

Ladson-Billings, G., \& Tate, W. F. IV. (1995). Toward a critical race theory of education. Teachers College Record, 97(1), 47-68.

Ladson-Billings, G. (1994). The dreamkeepers: Successful teaching for AfricanAmerican students. San Francisco, CA: Jossey-Bass.

McLaren, P. (2003). Life in schools: An introduction to critical pedagogy in the foundations of education (4th ed.). Boston, MA: Pearson Education.

Nieto, S. (1995). From brown heroes and holidays to assimilationist agendas: Reconsidering the critiques of multicultural education. In C. E. Sleeter \& P. L. McLaren (Eds.), Multicultural education, critical pedagogy, and the politics of difference (pp. 191-220). Albany, NY: State University of New York Press.

Nieto, S. (2009). Multicultural education in the United States: Historical realities, ongoing challenges, and transformative possibilities. In J. A. Banks (Ed.) The Routledge international companion to multicultural education (pp. 79-95). New York: Routledge.

North, C. E. (2009a). Teaching for social justice?: Voices from the front lines. Boulder, CO: Paradigm Publishers.

North, C. E. (2009b). The promise and perils of developing democratic literacy for social justice. Curriculum Inquiry, 39(4), 555-579.

Oakes, J., Lipton, M., Anderson, L., \& Stillman, J. (2016). Teaching to change the world (4th ed.). New York, NY: Routledge.

Paris, D. (2012). Culturally sustaining pedagogy: A needed change in stance, terminology, and practice. Educational Researcher, 41(3), 93-97.

Pray, J. L., \& King Jordan, I. (2010). The deaf community and culture at a crossroads: Issues and challenges. Journal of Social Work in Disability and Rehabilitation, 9(2-3), 168-193. doi: 10.1080/ 1536710X.2010.493486

Reagan, T. (1985). The Deaf as a linguistic minority: Educational considerations. Harvard Educational Review, 55(3), 265- 277.

Rong, X. L., \& Preissle, J. (1998). Educating immigrant students. Thousand Oaks, CA: Corwin Press. 
Scull, J., \& Winkler, A.M. (2011). Shifting trends in special education. Retrieved from http://files.eric.ed.gov/fulltext/ED520416.pdf

Simms, L., Rusher, M., Andrews, J. F., \& Coryell, J. (2008). Apartheid in deaf education: Examining workforce diversity. American Annals of the Deaf, 153(4), 384-395.

Sleeter, C. E. (2015, February). Deepening social justice teaching. Journal of Language \& Literacy Education. Retrieved from http://jolle.coe.uga.edu/wpcontent/uploads/2014/01/SSO_Feb2015_Template.pdf

Sleeter, C. E. (2008). Preparing white teachers for diverse students. In M. Cochran-Smith, S. Feiman-Nemser, \& D. J. McIntyre (Eds.), Handbook of research on teacher education: Enduring questions in changing contexts (3rd ed.) (pp. 559-582). New York, NY: Routledge and Association of Teacher Educators.

Ukpokodu, O. N. (2016). Realizing transformative learning and social justice education: Unpacking teacher education practice. In S. M. TomlinsonClarke \& D. L. Clarke (Eds.), Social justice and transformative learning: Culture and identity in the United States and South Africa (pp. 113-142). New York, NY: Routledge.

Ukpokodu, O. N. (2010). Pedagogies that foster transformative learning in a multicultural education course: A reflection. Journal of Praxis in Multicultural Education, 4(1). doi: 10.9741/2161-2978.1003

Ukpokodu, O. N. (2002). Breaking through preservice teachers' defensive dispositions in a multicultural education course: A reflective practice. Multicultural Education, 9(3), 25-33.

Warren, J. T., \& Hytten, K. (2004). The faces of whiteness: Pitfalls and the Critical Democrat. Communication Education, 53(4), 321-339.

\section{Author Contact}

Gloshanda Lawyer: glawyer@vols.utk.edu University of Tennessee, 2317 Dunford Hall, 915 Volunteer Blvd, Knoxville, TN 37916 